Article

\title{
Analytical Study on Sodium Alginate Based Hybrid Nanofluid Flow through a Shrinking/Stretching Sheet with Radiation, Heat Source and Inclined Lorentz Force Effects
}

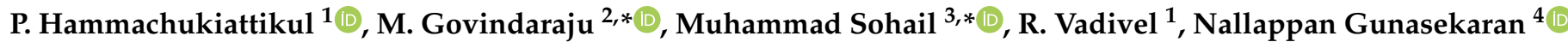 \\ and Sameh Askar ${ }^{5}$ (D) \\ 1 Department of Mathematics, Faculty of Science and Technology, Phuket Rajabhat University, \\ Phuket 83000, Thailand; porpattama@pkru.ac.th (P.H.); vadivelsr@yahoo.com (R.V.) \\ 2 Department of Mathematics, Padmavani Arts and Science College for Women, Periyar University, \\ Salem 636011, Tamil Nadu, India \\ 3 Department of Applied Mathematics and Statistics, Institute of Space Technology, 2750, \\ Islamabad 44000, Pakistan \\ 4 Department of Mathematical Sciences, Shibaura Institute of Technology, Saitama 337-8570, Japan; \\ gunasmaths@gmail.com \\ 5 Department of Statistics and Operations Research, College of Science, King Saud University, \\ Riyadh 11451, Saudi Arabia; saskar@ksu.edu.sa \\ * Correspondence: govimaths@gmail.com (M.G.); muhammad_sohail111@yahoo.com (M.S.)
}

check for updates

Citation: Hammachukiattikul, P.; Govindaraju, M.; Sohail, M.; Vadivel, R.; Gunasekaran, N.; Askar, S. Analytical Study on Sodium Alginate Based Hybrid Nanofluid Flow

through a Shrinking/Stretching Sheet with Radiation, Heat Source and

Inclined Lorentz Force Effects. Fractal Fract. 2022, 6, 68 .

https://doi.org/10.3390/

fractalfract6020068

Academic Editor: Lanre Akinyemi

Received: 25 October 2021

Accepted: 26 November 2021

Published: 27 January 2022

Publisher's Note: MDPI stays neutral with regard to jurisdictional claims in published maps and institutional affiliations.

Copyright: (c) 2022 by the authors. Licensee MDPI, Basel, Switzerland. This article is an open access article distributed under the terms and conditions of the Creative Commons Attribution (CC BY) license (https:/ / creativecommons.org/licenses/by/ $4.0 /)$.
Abstract: This study investigated the flow and heat transfer of sodium alginate-based hybrid nanofluids with a stretching/shrinking surface. The heat source/sink, Joule heating, inclined magnetic field, and thermal radiation influences are also examined in the designed model. The mixers of non-magnetic and magnetic nanoparticles are utilized, such as $\mathrm{Cu}$ and $\mathrm{Fe}_{3} \mathrm{O}_{4}$. The Casson fluid model is applied to determine the viscoplastic characteristics of sodium alginate (SA). The necessary governing SA-based hybrid nanofluid flow equations are solved analytically by hypergeometric function. SA-based hybrid nanofluid velocity, temperature, skin friction, and Nusselt number results are discussed in detail with various pertinent parameters, such as radiation, heat source/sink, inclined angle, magnetic field, Eckert number, and Casson parameters. It is noted that the dimensions of both $\mathrm{Cu}$ and $\mathrm{Fe}_{3} \mathrm{O}_{4}$ hybrid nanoparticles and Casson parameters are minimized by the momentum surface layer thickness. The magnetic field, radiation, heat source and Casson parameters serve to enhance the thermal boundary layer thickness. Finally, the current result was verified with previously published works.

Keywords: casson model; heat source/sink; hybrid nanofluid; hypergeometric function; thermal radiation

\section{Introduction}

The study of heat transfer and fluid flow produced by means of a stretching/shrinking surface and has a lot of industrial benefits, for example thermal insulation, manufacturing of composite materials, manufacturing of glass, underground species transport, drying of porous solids, oil recovery, and thermal solar systems. The primary industrial applications, heat transfer and flow investigation, are of significant consequence because the finishing manufactured quality is determined on the basis of the rate of convective heat exchange and the coefficient of the velocity gradient [1-10]. One of the advanced nanofluid types is a hybrid nanofluid containing two different nanoparticles suspended in the base fluid. The analysis of temperature transfer in a hybrid nanofluid has attracted significant previous research due to its ability to develop the temperature transfer rate compared to the usual nanofluids. For this reason, considerable applications involving temperature distributions such as electronic, transformer cooling, and coolant in machining have assumed hybrid nanofluids as the temperature transfer fluid. Mainly, nanofluid is distinguished as a 
high temperature distribution fluid compared with the usual fluid. However, this article investigated the hybrid nanofluid as a more enhanced thermal conduction rate compared with the usual nanofluid. The analysis of the thermal moment in radiative hybrid nanofluid flow with a thermal source on a rotating surface was proposed by [1]. They have determined the presence of thermal radiation, which improves the very high heat distribution in hybrid nanofluids. A numerical solution of hybrid nanofluid flow past a vertical surface with porous medium has been researched by [2]. A numerical solution of hybrid nanofluid past a porous stretching cylinder was studied by [3]. Very recently, several studies focused on a new type of hybrid nanofluid temperature distribution and flow process in [4-13].

Currently, a non-Newtonian fluid, sodium alginate (SA), has drawn much interest due to its biomedical and industrial uses, such as in pharmaceuticals, textiles, paper production, the food industry, and tissue formation. Both analytical and numerical solutions of SAbased nanofluid thermal transfer and flow analysis have been researched by [14]. The authors of [15] examined the SA-based nanofluids various flow and thermal transfer effects. Very recently, the authors in [16] studied the effect of an SA-based hybrid nanofluid through a shrinking/stretching sheet with a non-magnetic and magnetic nanoparticle combination. They found that SA-based hybrid nanofluids have a higher rate of thermal distribution than $\mathrm{H}_{2} \mathrm{O}$ based hybrid nanofluids.

Electrically conducting fluids with magnetic properties such as hydromagnetic field and surface layer flow and thermal conduction characteristics in the presence of magnetic field effects are a great benefit in the industry, such as for nuclear reactors and electromagnetic casting etc. The magnetohydrodynamic hybrid nanofluid flow and thermal convection through a shrinking/stretching sheet has been examined by [17]. Magnetic force effect on hybrid nanofluid past a circular cavity has been analyzed by [18]. Hybrid nanofluid through a porous medium with magnetic force was analyzed by [19]. The effect of a magnetic field on hybrid nanofluids past a permeable tank was researched by [20]. The authors in [21] studied the effect of hybrid nanofluid flow with a magnetic stagnation point flow on a vertical flat plate. The impact of magnetic force on hybrid nanofluid free convection was researched by [22]. Recently, Ref. [23] researched the magnetic force and uniform heat source/sink effect on hybrid nanofluid flow through stretching/shrinking.

One of the important thermal distributions is thermal radiation. In particular, numerous engineering effects occur at great temperatures, and thus thermal radiation knowledge plays a noteworthy part in the layout of the application apparatus. Thermal radiation has some most important parts in many industrial treatments, such as glass production, boiler design and, in addition, space improvement applications such as solar radiation, propulsion systems,space vehicles, aerodynamics, combustion processes, internal combustion engines, rockets, and ship compressors. Considering these, a small number of scholars have planned commitments for the inspection of magnetohydrodynamic nanofluid streams with thermal radiation phenomena. The thermal radiation impact on hybrid nanofluid flow with a stretching/shrinking surface was investigated by [24]. They found that the impact of radiation enhances the heat flux on the surface, and therefore generates the upper thermal heat in the viscous dominant region. The authors in [25] studied the effect of thermal radiation on hybrid nanofluid flow through a nonlinear stretching surface. Ref. [26] studied the thermal radiation of hydromagnetic hybrid nanofluid with Joule heating effects. To the best of the author's knowledge, up till now, no theoretical results for the analytical study on sodium alignate-based magnetic and non-magnetic nanoparticles combination in radiative hybrid nanofluids with an inclined Lorentz force. This is the major inspiration of our current study.

The objective of the current research article is to directly apply the theory of SA-based hybrid nanofluid flow on a stretching/shrinking surface and heat source/sinks. The magnetic field, thermal radiation, and Joule heating with viscoplastic characteristics are researched analytically. The governing equations are solved using hypergeometric functions; the results are discussed with the help of graphs. Finally, our results are compared with previously published articles. 
The paper is structured as follows: The explanation of the physical form is arranged in Section 2. In this part, we have considered formulation of the problem for the 2-Dimensional incompressible flow of magnetic and non-magnetic SA-based hybrid nanofluids have been presented. Section 3 is devoted to the result of these model equations by the hypergeometric function method. The results and discussion has been presented in Section 4. Finally, the major results of the present article have been given in Section 5 .

\section{Formulation of the Problem}

To develop the model, we considered the study of a compressible two-dimensional SA-based hybrid nanofluid through a shrinking/stretching sheet with inclined magnetic field. The purpose of thermal radiation and uniform heat generation/absorption are also incorporated in the thermal transfer analysis. Assumption of frame coordinates where $\mathrm{x}$-axis along with the sheet's horizontal surface, while $\mathrm{y}$-axis measures the normal to the surface. The shrinking/stretched velocity is considered as $u_{w}(x)=a x$, where ' $a$ ' is a constant. Here, we assume the surface and constant ambient temperature are $T_{w}(x)$ and $T_{\infty}$ respectively. Iron oxide $\left(\mathrm{Fe}_{3} \mathrm{O}_{4}\right)$ and Copper $(\mathrm{Cu})$ nano-size particles having sodium alginate as their base fluid are examined in the present article. Thermophysical properties of the nanoparticles and base fluids are given in Table 1. The constitutive connection for viscoplastic non-Newtonian fluid, given by [16,27], is

$$
\tau_{i j}= \begin{cases}\tau_{i j}=2\left(\mu_{B}+\frac{\sigma_{y}}{\sqrt{2 \pi}}\right) e_{i j}, & \pi>\pi_{c} \\ \tau_{i j}=2\left(\mu_{B}+\frac{\sigma_{y}}{\sqrt{2 \pi_{c}}}\right) e_{i j}, & \pi<\pi_{c}\end{cases}
$$

where $\pi=e_{i j} e_{i j}$ and $e_{i j}$ is given by

$$
e_{i j}=\frac{1}{2}\left(\frac{\partial v_{i}}{\partial x_{i}}+\frac{\partial v_{j}}{\partial x_{i}}\right)
$$

with $1 \leq i, j \leq 2$, the governing equations are given as [24]

$$
\begin{gathered}
\frac{\partial u}{\partial x}+\frac{\partial v}{\partial y}=0 \\
u \frac{\partial u}{\partial x}+v \frac{\partial u}{\partial y}=v_{h n f}\left(1+\frac{1}{\Gamma}\right) \frac{\partial^{2} u}{\partial y^{2}}-\frac{\sigma_{h n f}}{\rho_{h n f}} B_{0}^{2} u \sin ^{2} \gamma \\
\left(\rho c_{p}\right)_{h n f}\left(u \frac{\partial T}{\partial x}+v \frac{\partial T}{\partial y}\right)=k_{h n f} \frac{\partial^{2} T}{\partial y^{2}}-\mu_{h n f}\left(1+\frac{1}{\Gamma}\right)\left(\frac{\partial u}{\partial y}\right)^{2}+Q\left(T-T_{\infty}\right)-\frac{\partial q_{r}}{\partial y},
\end{gathered}
$$

where $\Gamma=\mu_{B} \sqrt{2 \pi_{C}} / \sigma_{y}$ is the viscoplastic parameter for non-Newtonian fluid. which depends on give-in flow and stress only happens in the method when the important shear stress is larger than the give-in stress. Here $y$ and $x$ are the perpendicular and coordinates along the sheet, $v$ and $u$ are velocity components $y$ and $x$ directions, respectively, $Q$ is the uniform heat generation/absorption coefficient and $q_{r}$ is the radiative heat flux.

Table 1. Thermophysical properties of $\mathrm{SA}, \mathrm{H}_{2} \mathrm{O}, \mathrm{Cu}, \mathrm{Fe}_{3} \mathrm{O}_{4}$.

\begin{tabular}{ccccc}
\hline & $\mathbf{S A}$ & $\mathbf{H}_{\mathbf{2}} \boldsymbol{O}$ & $\mathrm{Cu}$ & $\boldsymbol{F e}_{3} \boldsymbol{O}_{\mathbf{4}}$ \\
\hline$\rho\left(\mathrm{kg} / \mathrm{m}^{3}\right)$ & 989 & 997.1 & 8933 & 5180 \\
$\mathrm{C}_{p}(\mathrm{~J} / \mathrm{kgK})$ & 4175 & 4179 & 385 & 670 \\
$K(\mathrm{~W} / \mathrm{mK})$ & 0.6376 & 0.613 & 401 & 9.7 \\
$\sigma(\Omega \mathrm{m})^{-1}$ & $2.6 \times 10^{-4}$ & 0.05 & $5.96 \times 10^{7}$ & $2.5 \times 10^{-4}$ \\
\hline
\end{tabular}


The effective density of the hybrid nanofluid $\rho_{h n f}, \sigma_{h n f}$ is hybrid nanofluid electric conductivity, hybrid nanofluid effective dynamic viscosity is $\mu_{h n f}$, heat capacitance $\left(\rho C_{p}\right)_{h n f}$ and the thermal conductivity $k_{h n f}$ of the hybrid nanofluid are given as

$$
\begin{aligned}
& \mu_{h n f}=\frac{\mu_{f}}{\left(1-\phi_{\mathrm{Cu}}-\phi_{\mathrm{Fe}_{3} \mathrm{O}_{4}}\right)^{2.5}}, \rho_{h n f}=\left(1-\phi_{\mathrm{C} u}-\phi_{\mathrm{Fe}_{3} \mathrm{O}_{4}}\right) \rho_{f}+\phi_{\mathrm{Cu}} \rho_{\mathrm{Cu}}+\phi_{\mathrm{Fe}_{3} \mathrm{O}_{4}} \rho_{\mathrm{Fe}_{3} \mathrm{O}_{4}} \text {, }
\end{aligned}
$$

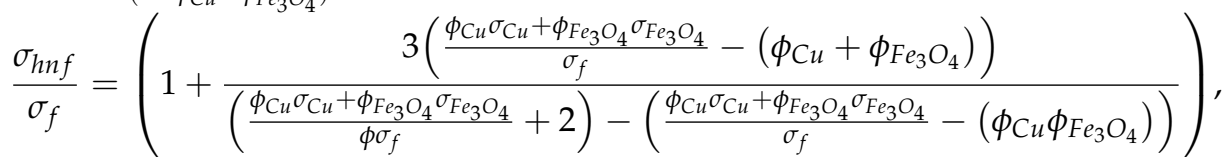

$$
\begin{aligned}
& \frac{K_{h n f}}{K_{f}}=\left(\frac{\left(\frac{\phi_{\mathrm{Cu}} K_{\mathrm{Cu}}+\phi_{\mathrm{Fe}_{3} \mathrm{O}_{4}} \mathrm{~K}_{\mathrm{Fe}_{3} \mathrm{O}_{4}}}{\phi}+2 K_{f}+2\left(\phi_{\mathrm{Cu}} K_{\mathrm{Cu}}+\phi_{\mathrm{Fe}_{3} \mathrm{O}_{4}} K_{\mathrm{Fe}_{3} \mathrm{O}_{4}}\right)-2 \phi K_{f}\right)}{\left(\frac{\phi_{\mathrm{C} u} K_{\mathrm{Cu}}+\phi_{\mathrm{Fe}_{3} \mathrm{O}_{4}} K_{\mathrm{Fe}_{3} \mathrm{O}_{4}}}{\phi}+2 K_{f}+\left(\phi_{\mathrm{C} u} K_{\mathrm{Cu}}+\phi_{\mathrm{Fe}_{3} \mathrm{O}_{4}} K_{\mathrm{Fe}_{3} \mathrm{O}_{4}}\right)-\phi K_{f}\right)}\right) \text {. }
\end{aligned}
$$

The surface conditions of Equations (3)-(5) are

$$
\begin{aligned}
& u=\alpha u_{w}(x), \quad v=0, \quad y=0 ; \quad u \rightarrow 0 \text { as } \\
& T=T_{w}(x)=T_{\infty}+A x^{2} \quad \text { at } \quad y=0 ; \quad T \rightarrow T_{\infty} \quad \text { as } \quad y \rightarrow \infty .
\end{aligned}
$$

The radiation (see [24]) we have

$$
q_{r}=-\frac{4 \sigma^{*}}{3 k^{*}} \frac{\partial T^{4}}{\partial y} .
$$

Here, $k^{*}$ is the coefficient of absorption and $\sigma^{*}$ is the Stefan-Boltzmann constant. The solution of $T^{4}$ about $T_{\infty}$ is given,

$$
T^{4} \cong 4 T_{\infty}^{3} T-3 T_{\infty}^{4} .
$$

From Equation (5) is given by

$$
\begin{aligned}
\left(\rho c_{p}\right)_{h n f}\left(u \frac{\partial T}{\partial x}+v \frac{\partial T}{\partial y}\right)= & k_{h n f} \frac{\partial^{2} T}{\partial \bar{y}^{2}}-\mu_{h n f}\left(1+\frac{1}{\Gamma}\right)\left(\frac{\partial u}{\partial y}\right)^{2}+Q\left(T-T_{\infty}\right) \\
& +\frac{16 \sigma^{*} T_{\infty}^{3}}{3 k^{*}} \frac{\partial^{2} T}{\partial y^{2}} .
\end{aligned}
$$

Now, we set up the transformations of similarity as

$$
\eta=y \sqrt{\frac{a}{v_{f}}}, u=a x F^{\prime}(\eta), v=-\sqrt{a v_{f}} F(\eta), \theta(\eta)=\frac{T-T_{\infty}}{T_{w w}-T_{\infty}} .
$$

From Equations (4) and (10) can be written as

$$
\begin{array}{r}
\frac{A_{1}}{A_{2}}\left(1+\frac{1}{\Gamma}\right) F^{\prime \prime \prime}(\eta)+F(\eta) F^{\prime \prime}(\eta)-F^{\prime 2}(\eta)-M \frac{A_{3}}{A_{2}} F^{\prime}(\eta) \sin ^{2} \gamma=0 \\
\frac{A_{4}}{P r}\left(A_{5}+\frac{4}{3} N r\right) \theta^{\prime \prime}(\eta)+F(\eta) \theta^{\prime}(\eta)-2 F^{\prime}(\eta) \theta(\eta)+\delta A_{4} \theta(\eta) \\
-A_{4} A_{1}\left(1+\frac{1}{\Gamma}\right) E c F^{\prime \prime 2}(\eta)=0
\end{array}
$$

with

$$
\begin{aligned}
& F(\eta)=0, F^{\prime}(\eta)=\alpha, \theta(\eta)=1 ; \text { at } \eta=0, \\
& F^{\prime}(\eta) \rightarrow 0, \quad \theta(\eta) \rightarrow 0 \text { as } \quad \eta \rightarrow \infty
\end{aligned}
$$


Here $\operatorname{Pr}=\frac{\left(\rho C_{p}\right)_{f} v_{f}}{K_{f}}, N r=\frac{16 \sigma^{*} T_{\infty}^{3}}{3 k k^{*}}, E c=\frac{a^{2}}{A\left(C_{p}\right)_{f}}, M=\frac{\sigma_{f} B_{0}^{2}}{a \rho_{f}}, \delta=\frac{Q}{a\left(\rho C_{p}\right)_{f}}, A_{1}=\frac{\mu_{h n f}}{\mu_{f}}$, $A_{2}=\frac{\rho_{h n f}}{\rho_{f}}, A_{3}=\frac{\sigma_{h n f}}{\sigma_{f}}, A_{4}=\frac{\left(\rho c_{p}\right)_{f}}{\left(\rho c_{p}\right)_{h n f}}, A_{5}=\frac{K_{h n f}}{K_{f}}$.

The skin friction coefficients $C_{f x}$ and Nusselt number $N u_{x}$ are

$$
R e_{x}^{1 / 2} C_{f x}=\frac{1}{\left(1-\phi_{\mathrm{C} u}-\phi_{\mathrm{Fe}_{2} \mathrm{O}_{4}}\right)^{2.5}} \frac{\rho_{f}}{\rho_{h n f}}\left(1+\frac{1}{\Gamma}\right) F^{\prime \prime}(0), R e_{x}^{-1 / 2} N u_{x}=-\frac{K_{h n f}}{K_{f}} \theta^{\prime}(0) .
$$

where $R e_{x}=u_{x} x / v_{f}$ is the local Reynolds number.

\section{Analytical Solution of Flow and Thermal Field}

According to [16,28], the considered the correct solution of Equation (12)

$$
F(\eta)=\frac{\alpha}{m}\left(1-e^{-m \eta}\right)
$$

where $m=\sqrt{\left(1-\phi_{\mathrm{Cu}}-\phi_{\mathrm{Fe}_{2} \mathrm{O}_{4}}\right)^{2.5}\left(\frac{\Gamma}{1+\Gamma}\right)\left(\alpha \frac{\rho_{h n f}}{\rho_{f}}+M \sin ^{2} \gamma \frac{\sigma_{h n f}}{\sigma_{f}}\right)}$.

Using above equation in Equation (13), we get

$$
\begin{gathered}
\omega \theta^{\prime \prime}(\eta)+\operatorname{Pr}\left(\frac{\alpha}{m}-\frac{\alpha}{m} e^{-m \eta}\right) \theta^{\prime}(\eta)-2 \operatorname{Pr} \alpha e^{-m \eta} \theta(\eta)+\delta \operatorname{Pr} A_{4} \theta(\eta) \\
-\operatorname{Pr}_{4} A_{1}\left(1+\frac{1}{\Gamma}\right) E c \alpha^{2} m^{2} e^{-2 m \eta}=0 .
\end{gathered}
$$

Now, introduce the new variable $\xi=-\frac{P r e^{-m \eta}}{\omega m^{2}}$ in Equation (17), we get

$$
\xi \theta_{\xi \xi}+\left(1-a_{0}-\xi\right) \theta_{\xi}+\left(2+\frac{\delta A_{4} P r}{\omega m^{2} \xi}\right) \theta(\xi)=-A_{4} A_{1}\left(1+\frac{1}{\Gamma}\right) E c \alpha m^{2} e^{-m \eta}
$$

From Equation (14) becomes

$$
\theta(\xi)=1, \quad \theta(0)=0 .
$$

From Equations (18) and (19) we get

$$
\theta(\eta)=C_{1} e^{-m \frac{a_{0}+b_{0}}{2} \eta} M\left[\frac{a_{0}+b_{0}-4}{2}, b_{0}+1,-\frac{\operatorname{Pr} \alpha}{\omega m^{2}} e^{-m \eta}\right]+C_{2} e^{-2 m \eta},
$$

where $M\left[a_{0}, a_{0}+1,-b_{0} e^{-m \eta}\right]$ is the hypergeometric function. which is given as in [29], where

$$
\begin{aligned}
& C_{1}=\frac{1-C_{2}}{M\left[\frac{a_{0}+b_{0}-4}{2}, b_{0}+1,-\frac{P r \alpha}{\omega m^{2}} e^{-m \eta}\right]}, \quad C_{2}=-\frac{A_{4} A_{1}\left(1+\frac{1}{\Gamma}\right) E c \alpha m^{2}}{4-2 a_{0}+\frac{\delta A_{4} P r}{\omega m^{2}}}, a_{0}=\frac{\alpha P r}{\omega m^{2}} \\
& b_{0}=\sqrt{a_{0}^{2}-\frac{4 \delta P r A_{4}}{\omega m^{2}}}, \quad \text { and } \omega=\frac{3 A_{4} A_{5}+4 N r}{3} .
\end{aligned}
$$

The Nusselt number $N u_{x}$ which is defined as

$$
N u_{x}=\frac{\alpha x q_{w}}{k_{f}\left(T_{w}-T_{\infty}\right)}
$$

where $q_{w}=-\left(k_{h n f}+\frac{16 \sigma T_{\infty}^{3}}{3 k^{*}}\right)\left(\frac{\partial T}{\partial y}\right)_{y=0}$ is the heat flux of the local surface and we obtain:

$$
R e_{x}^{-1 / 2} N u_{x}=\frac{k_{h n f}}{k_{f}}\left(\frac{3 N r+4}{3 N r}\right)\left[-\theta^{\prime}(0)\right]
$$


where

$$
\theta^{\prime}(0)=-C_{1} m \frac{a_{0}+b_{0}}{2} M\left[\frac{a_{0}+b_{0}-4}{2}, b_{0}+1,-\frac{P r \alpha}{\omega m^{2}}\right]+C_{1} \frac{a_{0}+b_{0}-4}{2\left(1+b_{0}\right)} \frac{\alpha P r}{\omega m} M\left[\frac{a_{0}+b_{0}}{2}-1, b_{0}+2,-\frac{P r \alpha}{\omega m^{2}}\right]
$$

\section{Graphical Results and Discussion}

This section discusses the analytical results of SA-based MHD radiative hybrid nanofluid with heat source/sink, Joule heating and viscoplastic impacts. Tables 2 and 3 exhibits excellent comparative answers and given confidence on the method employed in this work. The effects of velocity, temperature, $f^{\prime \prime}(0)$ and $\theta^{\prime}(0)$ on magnetic, inclined angle, radiation, heat source/sink, Casson, Eckert number, and nanosolid volume fraction parameters are discussed. Figures 1 and 2 present the impact of shrinking $(\alpha<0)$ and stretching $(\alpha>0)$ cases on the velocity profile. It is observed that the enhancing value of shrinking/stretching parameter velocity of the SA-based hybrid nanofluid is also increased. The presence of both shrinking and stretching cases enhanced the thickness of the velocity boundary layer.

Table 2. Comparison solutions for $-F^{\prime \prime}(0)$ (skin friction coefficient). When $\phi_{\mathrm{Fe}_{3} \mathrm{O}_{4}}=M=\Gamma=\gamma=0$.

\begin{tabular}{cccc}
\hline$\phi_{\boldsymbol{C} u}$ & {$[30]$} & {$[31]$} & Present Results \\
\hline 0.05 & 1.10892 & 1.10892 & 1.10892 \\
0.1 & 1.17475 & 1.17475 & 1.17475 \\
0.15 & 1.20886 & 1.20886 & 1.20886 \\
0.2 & 1.21804 & 1.21804 & 1.21804 \\
\hline
\end{tabular}

Table 3. Comparison solutions for $-\theta^{\prime}(0)$ (Nusselt number). When $\phi_{C u}=\phi_{\mathrm{Fe}_{3} \mathrm{O}_{4}}=M=\gamma=\delta=$ $E c=\Gamma=0$.

\begin{tabular}{cccc}
\hline Pr & [32] & [31] & Present Results \\
\hline 0.72 & 1.0885 & 1.08852 & 1.08852 \\
1.0 & 1.3333 & 1.33333 & 1.33333 \\
3.0 & 2.5097 & 2.50973 & 2.50973 \\
10.0 & 4.7969 & 4.79687 & 4.79687 \\
100.0 & 15.7120 & 15.71163 & 15.71163 \\
\hline
\end{tabular}

The nanosolid volume fraction parameters $\phi_{\mathrm{C} u}$ and $\phi_{\mathrm{Fe}_{3} \mathrm{O}_{4}}$ on velocity profiles are illustrated in Figures 3 and 4, respectively. From these figures, enhancing the value of $\phi_{C u}$ and $\phi_{\mathrm{Fe}_{3} \mathrm{O}_{4}}$ in both cases, diminishes the velocity profile. This means that the enveloping value of a nanosolid can slow down the SA-based hybrid nanofluid velocity. The enlarged density of the fluid, contributes to the reduction in velocity. Figure 5 shows the behavior of the Casson parameter on the velocity profile. From this figure one can see that SA-based hybrid nanofluid velocities slow down in the presence of enlarging value of the Casson parameter.

Inclined angle and magnetic parameters impact on $F^{\prime}(\eta)$ and $\theta(\eta)$ are illustrated in Figures 6 and 7. From these figures, the enlarging the value of inclined angle and magnetic parameters means that the magnetic field strength is improved at the same time that the SA-based hybrid nanofluid's velocity is reduced. The enlarging value of inclined angle and magnetic parameters with improving the SA-based hybrid nanofluid temperature is shown in Figure 7. Physically, the presence of the inclined angle the and magnetic parameters slow down the fluid, while at the same time suddenly increasing heat transfer. 


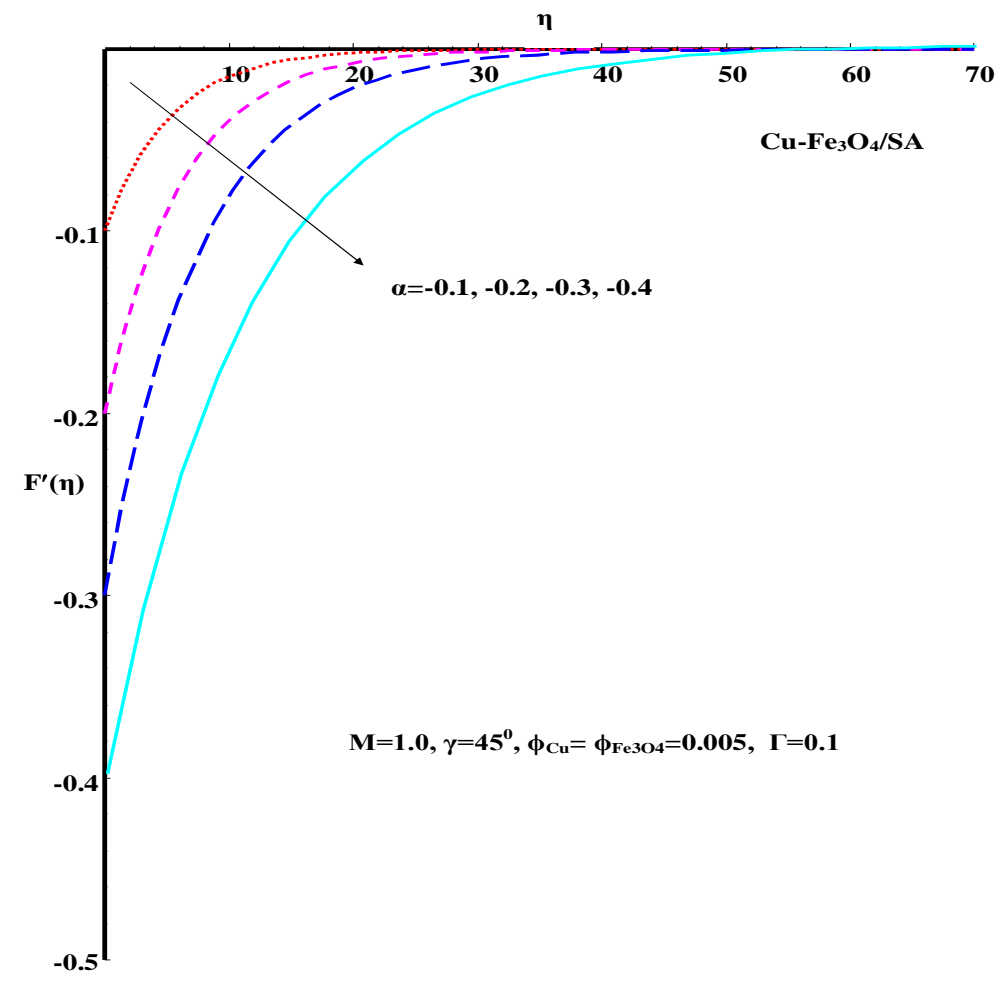

Figure 1. Effect of shrinking $(\alpha<0)$ case on velocity profile.

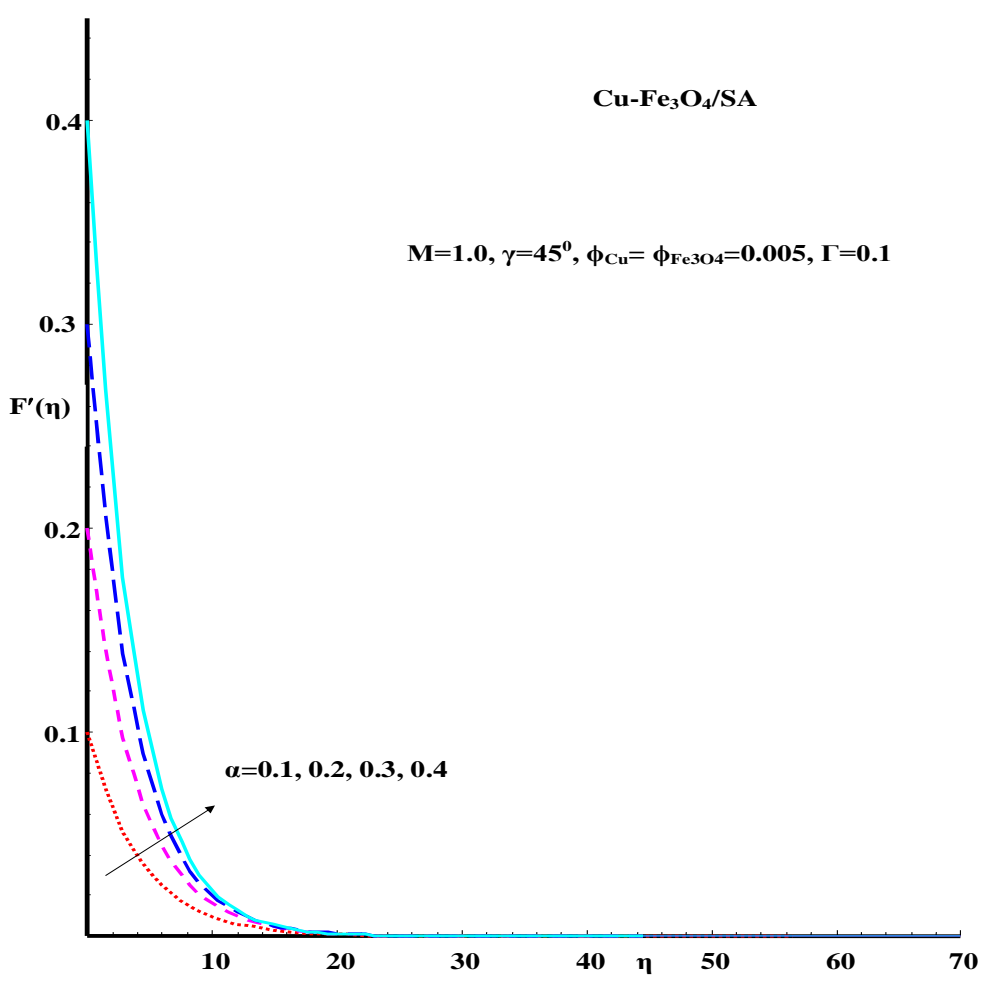

Figure 2. Effect of stretching $(\alpha>0)$ case on velocity profile. 


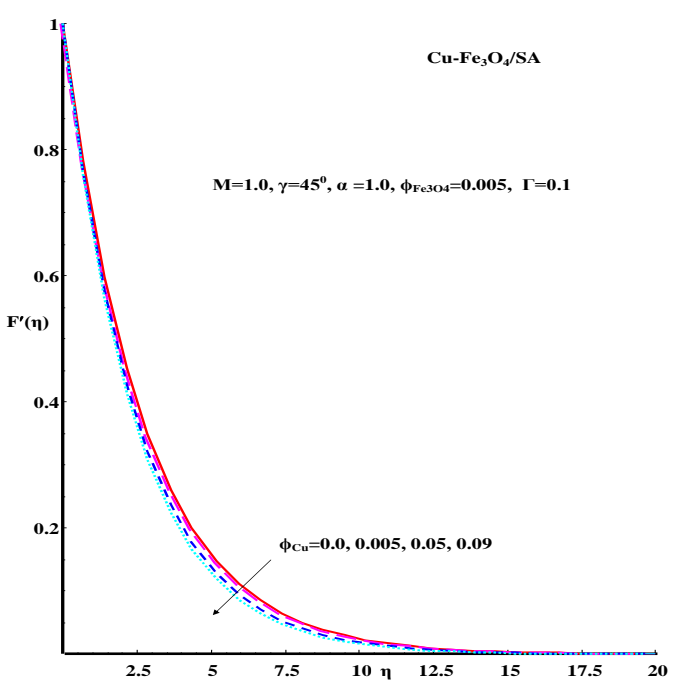

Figure 3. Effect of velocity variation of $C u / S A$ hybrid nanofluid.

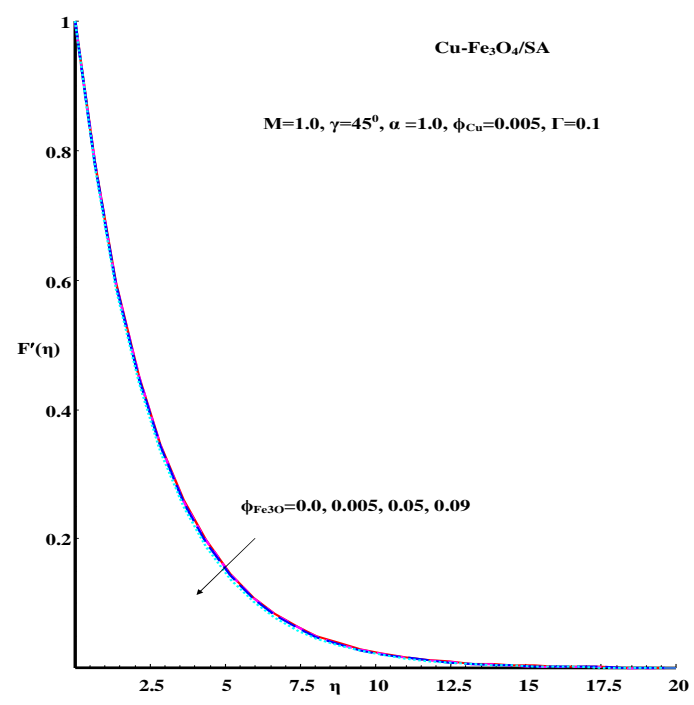

Figure 4. Effect of velocity variation of $\mathrm{Fe}_{3} \mathrm{O}_{4} / \mathrm{SA}$ hybrid nanofluid.

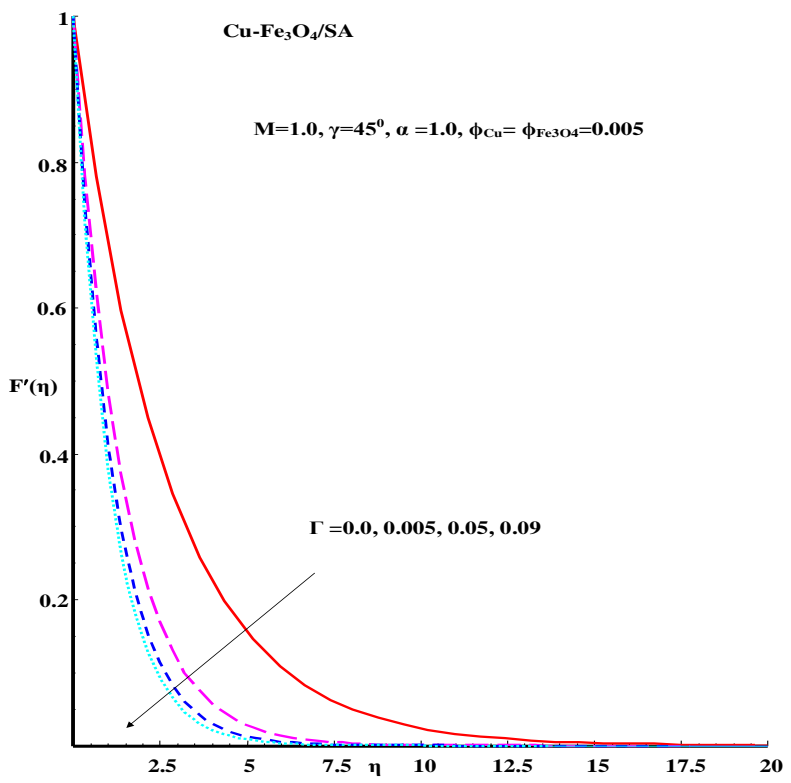

Figure 5. Effect of Casson parameter on velocity profile. 


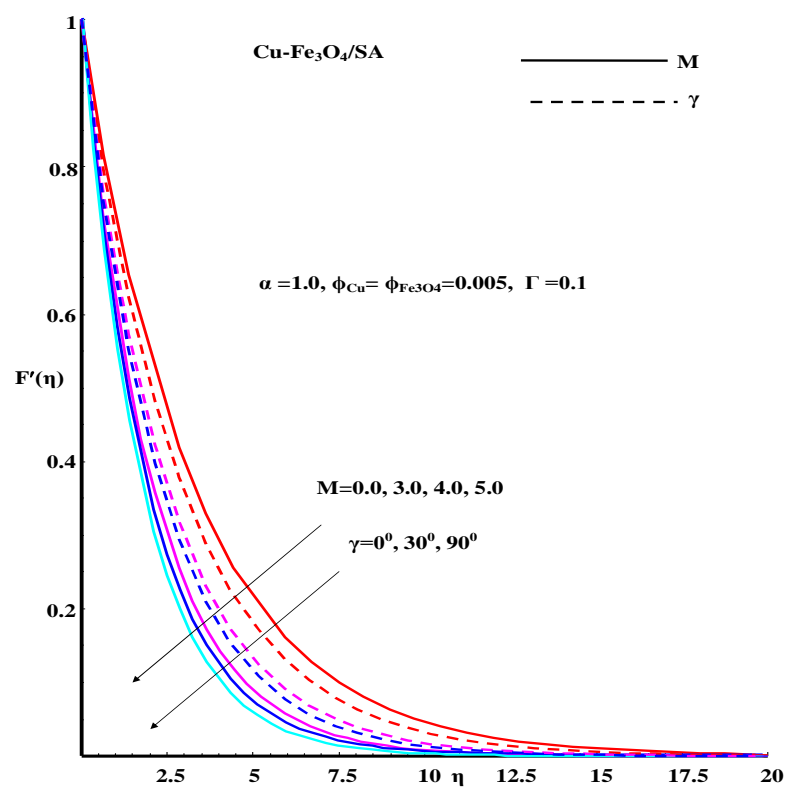

Figure 6. Effect of $M$ and inclined angle parameters on velocity profile.

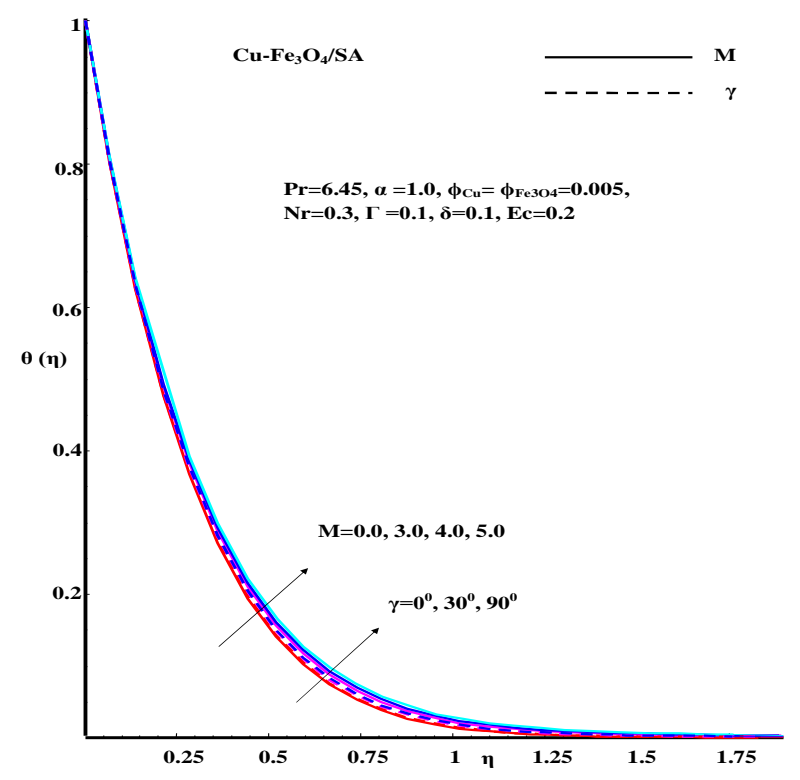

Figure 7. Effect of $M$ and inclined angle parameters on temperature profile.

Figure 8 displays to the impact of both the Ec and Casson parameter on the temperature profile. From these figures, it is observed that the thermal effect of the fluid is higher for higher estimations of both the Eckert number and Casson parameter. Furthermore, the thermal surface layer thickness is developed for the higher value of the $E c$ and $\Gamma$. These two parameters enhance the heat conduction in SA-based hybrid nanofluids. Figure 9 illustrates the consequences of heat source/sink and radiation parameters on $\theta(\eta)$. These plots show that both the thermal surface thickness and temperature profiles are increased with the heat source and radiation parameters. Actually, enhancing the heat surface layer thickness may minimize the thermal flux on the surface, which minimized the temperature profile. 


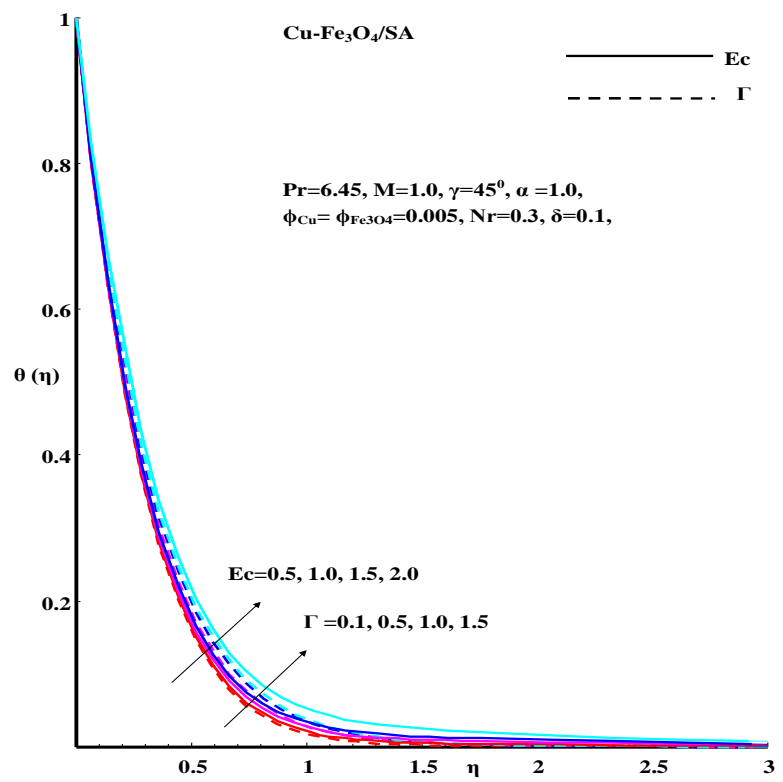

Figure 8. Effect of Eckert number and Casson parameters on temperature profile.

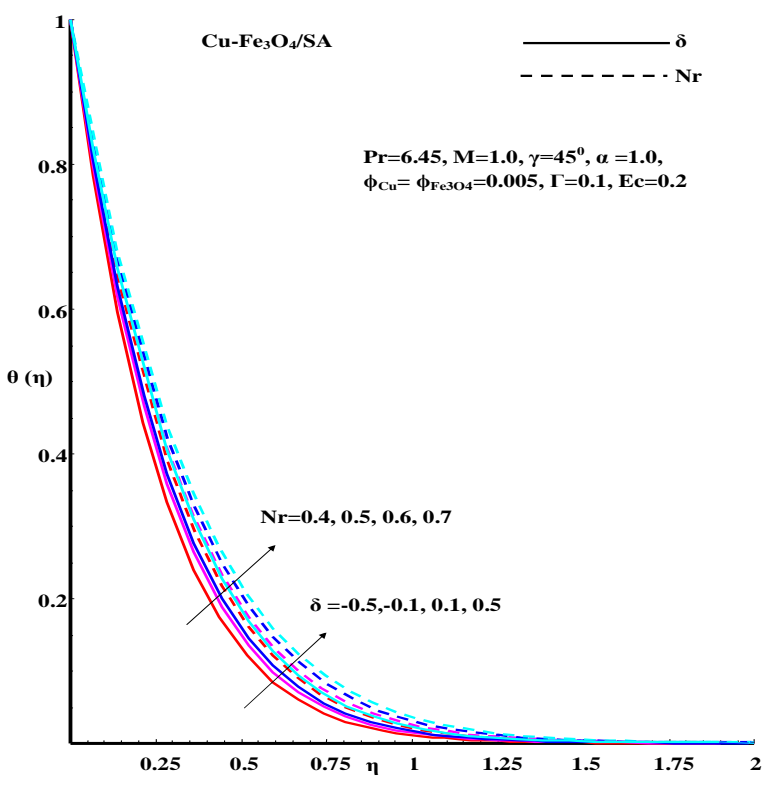

Figure 9. Effect of $\mathrm{Nr}$ and heat source/sink parameters on temperature profile.

Figure 10 presents the effect of the inclined magnetic field on the $F^{\prime \prime}(0)$. Enhancing the values of the inclined angle and magnetic field lead to reduced skin friction. Physically, the enhancing of magnetic field strength means the skin friction coefficient was minimized. The Casson parameter and nanosolid volume fraction parameters on the $F^{\prime \prime}(0)$ are shown in Figure 11. It is evident that $F^{\prime \prime}(0)$ is reduced with the enhancing value of both Casson and nanosolid volume fraction parameters.

Figure 12 displays the impact of the $E c$ and heat source/sink parameters on the Nusselt number for SA-based hybrid nanofluids. The Nusselt number diminishes with the enlargement in the Eckert number and the heat sink parameter, indicating that the SA-based fluid should be utilized to get the maximum thermal transfer. Figure 13 shows the effect of radiation and Casson parameters on the Nusselt number for $\mathrm{Cu}-\mathrm{Fe}_{3} \mathrm{O}_{4} / \mathrm{SA}-$ based hybrid nanofluid. The $\theta^{\prime}(0)$ reduces with the enhancement in the $\mathrm{Nr}$ and Casson parameters. The exactness and confirmation of this solution are checked by comparing the current solutions for the coefficient of skin friction with those obtained previously by [30-32] as shown in Tables 2 and 3. 


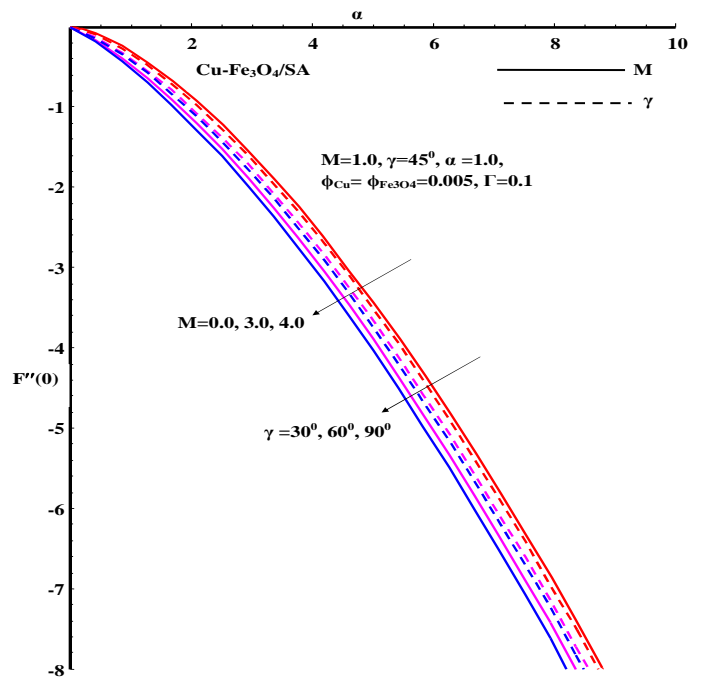

Figure 10. Effect of $M$ and inclined angle parameters on skin friction coefficient.

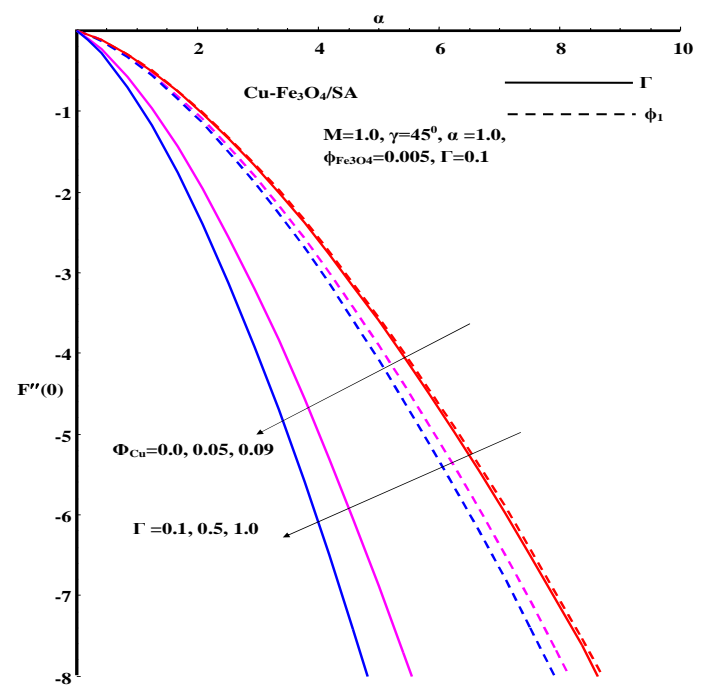

Figure 11. Effect of Casson parameter and $C u / S A$ hybrid nanofluid on skin friction coefficient.

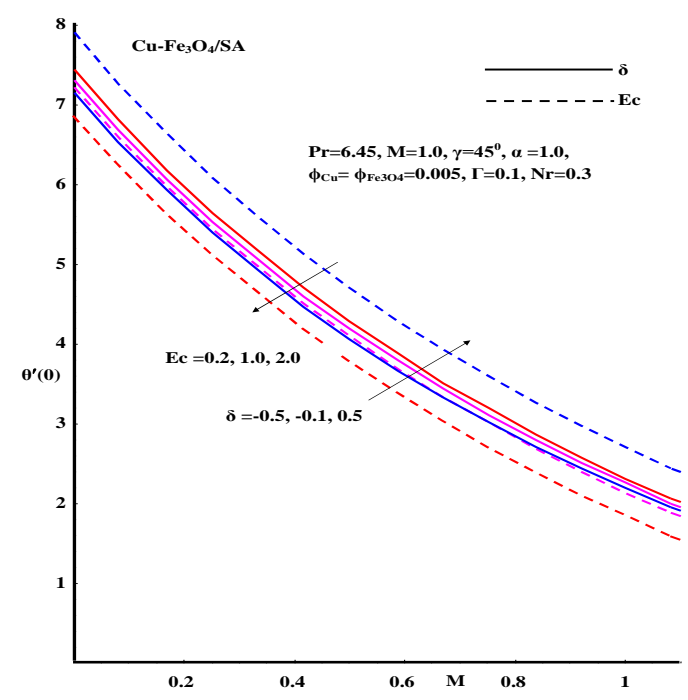

Figure 12. Effect of Eckert number and heat source/sink parameters on Nussult number. 


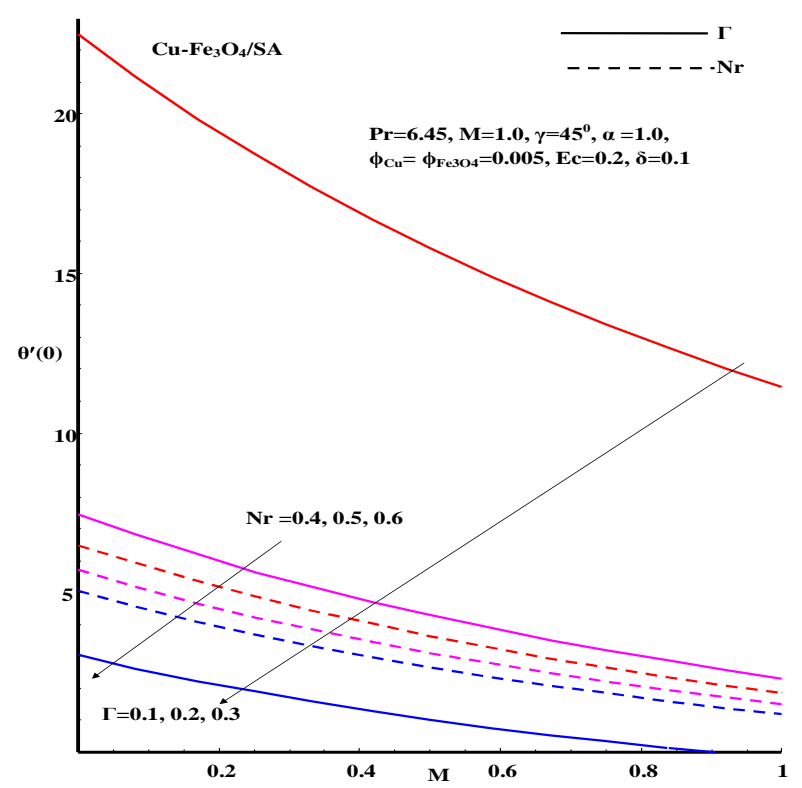

Figure 13. Effect of Casson and radiation parameters on Nussult number.

\section{Conclusions}

The impact of viscoplastic and thermal radiation on SA-based $\mathrm{Cu}-\mathrm{Fe}_{3} \mathrm{O}_{4}$ hybrid nanofluid flow with a shrinking/stretching surface was studied analytically. SA-based MHD radiative hybrid nanofluid flow, temperature, Nusselt number, and skin friction results are summarized below:

- $\quad$ SA based MHD radiative hybrid nanofluid velocity slows down the presence of the inclined magnetic field, the Casson parameter, and the nanoparticles. The presence of both shrinking and stretching enhanced the thickness of the velocity surface layer.

- The SA based MHD radiative hybrid nanofluid thermal conduction ability is enhanced when the values of the hybrid nanoparticle, Eckert number, Casson parameter, heat source, inclined magnetic field, and radiation parameter increase.

- $\quad$ The SA based hybrid nanofluid heat transfer rate is improved with the enhancing value of the heat source, and it decreases with the enhancing value of the radiation parameter, the Casson parameter, and the Eckert number.

Author Contributions: Conceptualization, M.G., M.S. and P.H.; Methodology, P.H. and R.V.; Software, S.A. and N.G.; Validation, P.H., M.S. and N.G.; Formal analysis, R.V. and N.G.; Investigation, S.A. and P.H.; Resources, M.S.; Data curation, M.G. and M.S.; Writing-original draft preparation, M.G., M.S. and P.H.; Writing-review and editing, M.G., M.S., P.H., R.V., N.G. and S.A.; Visualization, N.G., R.V. and P.H.; Supervision, R.V., N.G. and S.A.; Project administration, S.A.; Funding acquisition, S.A. All authors have read and agreed to the published version of the manuscript.

Funding: Research supporting project number (RSP-2022/167), King Saud University, Riyadh, Saudi Arabia.

Institutional Review Board Statement: Not applicable.

Informed Consent Statement: Not applicable.

Data Availability Statement: Not applicable.

Conflicts of Interest: The authors declare that they have no competing interests. 


\section{Nomenclature}

\begin{tabular}{|c|c|}
\hline$A$ & constant parameter $\left[\mathrm{Km}^{-2}\right]$ \\
\hline$B_{0}$ & Uniform Magnetic field strength $\left[\mathrm{kgs}^{-2} \mathrm{~A}^{-1}\right]$ \\
\hline$C_{p, f}$ & Specific heat (SA) $\left[\mathrm{Jkg}^{-1} \mathrm{~K}^{-1}\right]$ \\
\hline$C_{p, C u}$ & $\mathrm{Cu}$ specific heat capacity $\left[\mathrm{Jkg}^{-1} \mathrm{~K}^{1}\right]$ \\
\hline $\mathrm{C}_{\mathrm{p}, \mathrm{Fe}_{3} \mathrm{O}_{4}}$ & Specific heat $\left(\mathrm{Fe}_{3} \mathrm{O}_{4}\right)\left[\mathrm{Jkg}^{-1} \mathrm{~K}^{-1}\right]$ \\
\hline$C_{p, h n f}$ & Specific heat of hybrid nanofluid $\left[\mathrm{Jkg}^{-1} \mathrm{~K}^{-1}\right]$ \\
\hline Ec & Eckert number \\
\hline$F^{\prime}$ & Dimensionless velocity \\
\hline$K_{f}$ & thermal conductivity (SA) $\left[\mathrm{Wm}^{-1} \mathrm{~K}^{-1}\right]$ \\
\hline $\mathrm{K}_{\mathrm{Fe}_{3} \mathrm{O}_{4}}$ & $\mathrm{Fe}_{3} \mathrm{O}_{4}$ thermal conductivity $\left[\mathrm{Wm}^{-1} \mathrm{~K}^{-1}\right]$ \\
\hline$K_{C u}$ & $\mathrm{Cu}$ thermal conductivity $\left[\mathrm{Wm}^{-1} \mathrm{~K}^{-1}\right]$ \\
\hline$K_{h n f}$ & Hybrid nanofluid thermal conductivity $\left[\mathrm{Wm}^{-1} \mathrm{~K}^{-1}\right]$ \\
\hline$M$ & Magnetic parameter \\
\hline$N r$ & Radiation parameter \\
\hline $\operatorname{Pr}$ & Prandtl number \\
\hline$T$ & hybrid nanofluid Temperature $[K]$ \\
\hline$T_{w}$ & Surface temperature $[K]$ \\
\hline$T_{\infty}$ & Ambient temperature $[K]$ \\
\hline \multicolumn{2}{|c|}{ Greek Symbols } \\
\hline$\alpha$ & shrinking/Stretching parameter \\
\hline$\gamma$ & inclined angle parameter \\
\hline$\Gamma$ & Viscoplastic parameter \\
\hline$\phi$ & Hybrid nanosolid volume fraction \\
\hline$\phi_{C u}$ & $\mathrm{Cu}$ nanosolid volume fraction \\
\hline$\phi_{\mathrm{Fe}_{3} \mathrm{O}_{4}}$ & $\mathrm{Fe}_{3} \mathrm{O}_{4}$ nanosolid volume fraction \\
\hline$\mu_{B}$ & Plastic dynamic viscosity $\left[\mathrm{kgm}^{-1} \mathrm{~s}^{-1}\right]$ \\
\hline$\mu f$ & SA dynamic viscosity $\left[\mathrm{kgm}^{-1} \mathrm{~s}^{-1}\right]$ \\
\hline$\mu_{h n f}$ & Hybrid nanofluid dynamic viscosity $\left[\mathrm{kgm}^{-1} \mathrm{~s}^{-1}\right]$ \\
\hline$\rho_{f}$ & SA density $\left[\mathrm{kgm}^{-3}\right]$ \\
\hline$\rho_{C u}$ & $\mathrm{Cu}$ density $\left[\mathrm{kgm}^{-3}\right]$ \\
\hline$\rho_{\mathrm{Fe}_{3} \mathrm{O}_{4}}$ & $\mathrm{Fe}_{3} \mathrm{O}_{4}$ density $\left[\mathrm{kgm}^{-3}\right]$ \\
\hline$\rho_{\text {hnf }}$ & Hybrid nanofluid density $\left[\mathrm{kgm}^{-3}\right]$ \\
\hline$\sigma_{f}$ & electric conductivity (SA) $\left[(\Omega m)^{-1}\right]$ \\
\hline$\sigma_{C u}$ & electric conductivity $(\mathrm{Cu})\left[(\Omega m)^{-1}\right]$ \\
\hline$\sigma_{\mathrm{Fe}_{3} \mathrm{O}_{4}}$ & $\mathrm{Fe}_{3} \mathrm{O}_{4}$ electric conductivity $\left[(\Omega m)^{-1}\right]$ \\
\hline$\sigma_{h n f}$ & Hybrid nanofluid electric conductivity $\left[(\Omega m)^{-1}\right]$ \\
\hline$\eta$ & Similarity variable \\
\hline$\theta$ & Dimensionless form of temperature \\
\hline \multicolumn{2}{|c|}{ Subscripts } \\
\hline $\mathrm{Cu}$ & Copper \\
\hline $\mathrm{Fe}_{3} \mathrm{O}_{4}$ & Iron oxide \\
\hline$h n f$ & Hybrid nanofluid \\
\hline
\end{tabular}

\section{References}

1. Hayat, T.; Nadeem, S. Heat transfer enhancement with Ag-CuO/water hybrid nanofluid. Results Phys. 2017, 7, 2317-2324. [CrossRef]

2. Waini, I.; Ishak, A.; Groşan, T.; Pop, I. Mixed convection of a hybrid nanofluid flow along a vertical surface embedded in a porous medium. Int. Commun. Heat Mass Transf. 2020, 114, 104565. [CrossRef]

3. Gholinia, M.; Armin, M.; Ranjbar, A.; Ganji, D. Numerical thermal study on CNTs $/ \mathrm{C}_{2} \mathrm{H}_{6} \mathrm{O}_{2}--\mathrm{H}_{2} \mathrm{O}$ hybrid base nanofluid upon a porous stretching cylinder under impact of magnetic source. Case Stud. Therm. Eng. 2019, 14, 100490. [CrossRef]

4. Tian, M.W.; Rostami, S.; Aghakhani, S.; Goldanlou, A.S.; Qi, C. A techno-economic investigation of 2D and 3D configurations of fins and their effects on heat sink efficiency of MHD hybrid nanofluid with slip and non-slip flow. Int. J. Mech. Sci. 2021, 189, 105975. [CrossRef]

5. Saeed, A.; Bilal, M.; Gul, T.; Kumam, P.; Khan, A.; Sohail, M. Fractional order stagnation point flow of the hybrid nanofluid towards a stretching sheet. Sci. Rep. 2021, 11, 1-15. [CrossRef] [PubMed] 
6. Zubair, T.; Usman, M.; Hamid, M.; Sohail, M.; Nazir, U.; Nisar, K.S.; Vijayakumar, V. Computational analysis of radiative Williamson hybrid nanofluid comprising variable thermal conductivity. Jpn. J. Appl. Phys. 2021, 60, 087004. [CrossRef]

7. Chu, Y.M.; Nazir, U.; Sohail, M.; Selim, M.M.; Lee, J.R. Enhancement in thermal energy and solute particles using hybrid nanoparticles by engaging activation energy and chemical reaction over a parabolic surface via finite element approach. Fractal Fract. 2021, 5, 119. [CrossRef]

8. Aghahadi, M.H.; Niknejadi, M.; Toghraie, D. An experimental study on the rheological behavior of hybrid Tungsten oxide $\left(\mathrm{WO}_{3}\right)$-MWCNTs/engine oil Newtonian nanofluids. J. Mol. Struct. 2019, 1197, 497-507. [CrossRef]

9. Shahsavar, A.; Godini, A.; Sardari, P.T.; Toghraie, D.; Salehipour, H. Impact of variable fluid properties on forced convection of $\mathrm{Fe}_{3} \mathrm{O}_{4} / \mathrm{CNT} /$ water hybrid nanofluid in a double-pipe mini-channel heat exchanger. J. Therm. Anal. Calorim. 2019, 137, 1031-1043. [CrossRef]

10. Barnoon, P.; Toghraie, D.; Eslami, F.; Mehmandoust, B. Entropy generation analysis of different nanofluid flows in the space between two concentric horizontal pipes in the presence of magnetic field: single-phase and two-phase approaches. Comput. Math. Appl. 2019, 77, 662-692. [CrossRef]

11. Swain, K.; Mebarek-Oudina, F.; Abo-Dahab, S. Influence of MWCNT/ $\mathrm{Fe}_{3} \mathrm{O}_{4}$ hybrid nanoparticles on an exponentially porous shrinking sheet with chemical reaction and slip boundary conditions. J. Therm. Anal. Calorim. 2021, 1-10. [CrossRef]

12. Mebarek-Oudina, F.; Fares, R.; Aissa, A.; Lewis, R.; Abu-Hamdeh, N. Entropy and convection effect on magnetized hybrid nano-liquid flow inside a trapezoidal cavity with zigzagged wall. Int. Commun. Heat Mass Transf. 2021, 125, 105279. [CrossRef]

13. Mebarek-Oudina, F.; Reddy, N.K.; Sankar, M. Heat source location effects on buoyant convection of nanofluids in an annulus. In Advances in Fluid Dynamics; Springer: Berlin/Heidelberg, Germany, 2021; pp. 923-937.

14. Hatami, M.; Ganji, D. Heat transfer and flow analysis for $\mathrm{SA}-\mathrm{TiO}_{2}$ non-Newtonian nanofluid passing through the porous media between two coaxial cylinders. J. Mol. Liq. 2013, 188, 155-161. [CrossRef]

15. Akinshilo, A.T.; Olofinkua, J.O.; Olaye, O. Flow and heat transfer analysis of the Sodium Alginate conveying Copper Nanoparticles between two parallel plates. J. Appl. Comput. Mech. 2017, 3, 258-266.

16. Hussanan, A.; Qasim, M.; Chen, Z.M. Heat transfer enhancement in sodium alginate based magnetic and non-magnetic nanoparticles mixture hybrid nanofluid. Phys. A Stat. Mech. Appl. 2020, 550, 123957. [CrossRef]

17. Aly, E.H.; Pop, I. MHD flow and heat transfer near stagnation point over a stretching/shrinking surface with partial slip and viscous dissipation: Hybrid nanofluid versus nanofluid. Powder Technol. 2020, 367, 192-205. [CrossRef]

18. Sheikholeslami, M.; Mehryan, S.; Shafee, A.; Sheremet, M.A. Variable magnetic forces impact on magnetizable hybrid nanofluid heat transfer through a circular cavity. J. Mol. Liq. 2019, 277, 388-396. [CrossRef]

19. Izadi, M.; Sheremet, M.A.; Mehryan, S. Natural convection of a hybrid nanofluid affected by an inclined periodic magnetic field within a porous medium. Chin. J. Phys. 2020, 65, 447-458. [CrossRef]

20. Sheikholeslami, M.; Shah, Z.; Shafee, A.; Kumam, P.; Babazadeh, H. Lorentz force impact on hybrid nanofluid within a porous tank including entropy generation. Int. Commun. Heat Mass Transf. 2020, 116, 104635. [CrossRef]

21. Zainal, N.A.; Nazar, R.; Naganthran, K.; Pop, I. MHD mixed convection stagnation point flow of a hybrid nanofluid past a vertical flat plate with convective boundary condition. Chin. J. Phys. 2020, 66, 630-644. [CrossRef]

22. Tlili, I.; Bhatti, M.; Hamad, S.M.; Barzinjy, A.A.; Sheikholeslami, M.; Shafee, A. Macroscopic modeling for convection of Hybrid nanofluid with magnetic effects. Phys. A Stat. Mech. Appl. 2019, 534, 122136. [CrossRef]

23. Jamaludin, A.; Naganthran, K.; Nazar, R.; Pop, I. MHD mixed convection stagnation-point flow of $\mathrm{Cu}-\mathrm{Al}_{2} \mathrm{O}_{3} /$ water hybrid nanofluid over a permeable stretching/shrinking surface with heat source/sink. Eur. J. Mech.-B/Fluids 2020, 84, 71-80. [CrossRef]

24. Khan, U.; Shafiq, A.; Zaib, A.; Baleanu, D. Hybrid nanofluid on mixed convective radiative flow from an irregular variably thick moving surface with convex and concave effects. Case Stud. Therm. Eng. 2020, 21, 100660. [CrossRef]

25. Sulochana, C.; Kumar, T.P. Heat and Mass Transfer of $\mathrm{Ag}-\mathrm{Fe}_{3} \mathrm{O}_{4} / \mathrm{H}_{2} \mathrm{O}$ hybrid nanofluid flow over a nonlinear stretching sheet. J. Crit. Rev. 2020, 7, 1566-1573.

26. Aziz, A.; Jamshed, W.; Ali, Y.; Shams, M. Heat transfer and entropy analysis of Maxwell hybrid nanofluid including effects of inclined magnetic field, Joule heating and thermal radiation. Discret. Contin. Dyn. Syst.-S 2020, 13, 2667. [CrossRef]

27. Casson, N. A flow equation for pigment-oil suspensions of the printing ink type. In Rheology of Disperse Systems; Pergamon Press: Oxford, UK, 1959.

28. Turkyilmazoglu, M. Multiple analytic solutions of heat and mass transfer of magnetohydrodynamic slip flow for two types of viscoelastic fluids over a stretching surface. J. Heat Transf. 2012, 134, 071701. [CrossRef]

29. Govindaraju, M.; Ganesh, N.V.; Ganga, B.; Hakeem, A.A. Entropy generation analysis of magneto hydrodynamic flow of a nanofluid over a stretching sheet. J. Egypt. Math. Soc. 2015, 23, 429-434. [CrossRef]

30. Hamad, M. Analytical solution of natural convection flow of a nanofluid over a linearly stretching sheet in the presence of magnetic field. Int. Commun. Heat Mass Transf. 2011, 38, 487-492. [CrossRef]

31. Kameswaran, P.; Narayana, M.; Sibanda, P.; Murthy, P. Hydromagnetic nanofluid flow due to a stretching or shrinking sheet with viscous dissipation and chemical reaction effects. Int. J. Heat Mass Transf. 2012, 55, 7587-7595. [CrossRef]

32. Grubka, L.; Bobba, K. Heat transfer characteristics of a continuous, stretching surface with variable temperature. J. Heat Transf. 1985, 107, 248-250. [CrossRef] 